\section{PENELITIAN PENGARUH CUACA TERHADAP PERUBAHAN SIFAT TEGANGAN PUTUS DAN PERPANJANGAN PUTUS BERBAGAI JENIS KULIT}

\section{OLEH :}

V. Sri Pertiwi R dan Hadi Mustofa

\section{Abstract}

The objective of the research is to find out the effect of weathering exosure on quality of leather by Weatherometer apparatus. During in door test y weather - Ometer, the condition of research is kept constanly i.e black panel $45^{\circ} \mathrm{C}$, dry bulb at $36^{\circ} \mathrm{C}$, wet bulb at $26^{\circ} \mathrm{C}$ and humidity at $45 \%$, specimen xposed taking over from the chamber for testing purpose were caried out every 5 hours and performed up to the limiting time at whice tensile strength and longation at break properties change.

\section{Intisari}

Penelitian ini bertujuan untuk mengetahui pengaruh cuaca terhadap muu kulit dengan alat Weather - Ometer. Dalam melaksanakan penelitian dengan lat Weather - Ometer, kondisi selama penelitian dipertahankan yaitu dengan lack panel $50^{\circ} \mathrm{C}$, dry bulb $36^{\circ} \mathrm{C}$, wet bulb $26^{\circ} \mathrm{C}$ dan kelembaban udara sebesar $5 \%$. Pengambilan cuplikan yang telah terkena penyinaran dari dalam alat unuk diuji dilaksanakan tiap 25 jam sekali, hal ini dilakukan sampai batas waktu imana terjadi perubahan sifat tegangan putus dan perpanjangan putus.

\section{Pendahuluan}

Kulit merupakan suatu produk alami yang berasal dari berbagai ternak antara lain kambing, domba, sapi, kerbau dan lain-lain, yang masing-masing menghasilkan suatu produk kulit jadi dengan mutu yang berbeda-beda. Adanya perbedaan tersebut disebabkan oleh beberapa faktor yang berupa bahan baku, proses, perlakuan yang diberikan serta kondisi dan lamanya penyimpanan.

Pada umumnya penyimpanan kulit jadi yang dilaksanakan saat ini hanya diletakkan disembarang tempat tanpa memperhatikan tentang ruang kondisi penyimpanan yang sesuai bagi produk kulit jadi, penyimpanan dengan cara demikian ini dapat mempengaruhi mutu produk barang jadinya.

Beberapa faktor penyebab tidak stabilnya kulit yang sering kali diklasifikasikan sebagai berikut :

1. Udara yang terpolusi dan kondisi serta perlakuan pada penyimpanan kulit

2. Timbulnya keringat dan adanya enzim berasal dari bakteri dan jamur.

Pengaruh dari udara terpolusi terhadap kulit samak nabati menurut hasil pengamatan STATER baik dengan penyamakan cepat maupun dengan penyamakan lambat, untuk kulit yang disimpan dalam ruangan yang udaranya kering maka zat taning yang terikat kolagen sangat lambat dan jumlahnya berkurang. Menurut hasil pengamatan yang dilakukan oleh FARADY bahwa produk gas buang pembakaran dapat merusakkan book binding, kulit lapis dan kopor, sedangkan serat - serat kulitnya menjadi rapuh dan masing-masing menjadi saling terpisah serta memberikan sifat yang disebut red rot,dari analisa powder diperoleh hasil kandungan asam dan sulfur pada tingkat yang sangat tinggi.

Daya tahan bookbinding kemungkinan lebih lama jika udara dalam ruang penyimpanan selalu berganti serta dihindarkan dari sinar mata hari secara langsung. Dari hasil pengamatannya INNEST mengatakan bahwa Bookbinding kulit lebih stabil yang diperoleh dari penyamakan dengan hidrolisa tanin dari pada disamak dengan kondensasi tanin. Pengaruh iklim dan ketahanannya untuk seluruh tipe kulit menurut hasil penelitian BOWES dan kawan-kawan terjadi penurunan sifat, hal ini disebabkan adanya kenaikan suhu dan kelembapan relatif udara yang tinggi sehingga dapat menyebabkan kulit kenampakannya menjadi gelap, retak serta kekuatannya berkurang secara nyata.

Adanya kerusakan pada kulit karena proteinnya mengalami degradasi menjadi dua bentuk rantai polipeptida serta struktur molekulnya yang tidak menentu, pemutusan secara hidrolisa pada rantai polipeptida terjadi pada 
lagen yang disimpan dalam keadaan panas dan lembab, maka keasaman kulit enjadi bertambah, sedangkan kekuatan tarik kulit dipengaruhi oleh peruhan struktur kulit, serabut-serabut kulit akan mengalami konstraksi dan kuatan tariknya menjadi rendah yang selanjutnya kekuatannya semakin turun a serabut kolagen mengalami pembengkakan yang disebabkan oleh air.

Menurut OFLAHERTY dan kawan-kawan 1978 bahwa adanya peningtan suhu, kelembapan dan kandungan substansi kulit (kolagen) dapat menyebkan penyerapan uap air oleh kulit, hal ini dapat mempengaruhi sifat phisis ri kulit jadi. Untuk mengetahui sampai seberapa jauh terjadinya penurunan at phisis terutama sifat tegangan putus dan perpanjangan putus, maka perlu canya diadakan suatu penelitian tentang pengaruh cuaca dengan menggukan alat Weather - Ometer terhadap sifat phisis kulit, dengan demikian peneian ini dilaksanakan yang tujuannya untuk mengetahui perubahan yang terdi pada berbagai jenis kulit akibat dari pengaruh cuaca, sehingga nantinya lam pelaksanaan penyimpanan produk kulit jadi kondisi tempenyimpanan endapat suatu perhatian.

ateri dan Metoda penelitian.

ateri penelitian terdiri dari :

Bahan, dalam melaksanakan penelitian ini diperlukan berbagai jenis kulit jadi antara lain berupa kulit boks berwarna coklat, kulit glace (skarlet), kulit jaket berwarna merah, kulit samak nabati (taklir) dan kulit samak nabati.

Alat yang diperlukan untuk penelitian antara lain pisau pons pembentuk contoh uji, pengukur ketebalan, alat uji tegangan putus, pengukur ketebalan dan Weather - Ometer.

letode Penelitian.

Bahan kulit jadi sebelum diberikan perlakuan cuaca terlebih dahulu ibuat cuplikan dalam bentuk dayung, yang selanjutnya dalam pelaksanaan enelitian cuplikan dalam alat Weather - Ometer CXW - 2. Selama penelitian erlangsung alat yang digunakan untuk pengujian diatur pada kondisi operasi ang tetap dengan suhu pada black panel $50^{\circ} \mathrm{C}$, dry bulb $36^{\circ} \mathrm{C}$, wet bulb $26^{\circ} \mathrm{C}$ erta kelembapan relatif sebesar $45 \%$, pengaturan kondisi demikian ini dengan enggunakan cam 7 pada cycle program, sehingga setiap 2 jam sekali penyiaran terjadi hujan buatan selama 18 menit dengan penyemprotan air sebesar 8 psi. Cuplikan yang dibuat dari bahan kulit jadi diperlakukan dalam alat ini elama 100 jam, dengan interval waktu pengambilan cuplikan tiap-tiap 25 jam kali, yang selanjutnya diadakan pengujian terhadap sifat phisisnya yang erupa tegangan putus dan perpanjangan putus masing-masing dengan dua kali ulangan.

Hasil Penelitian Dan Pembahasan.

Kulit jadi yang berasal dari berbagai jenis dan sudah mendapatkan perla kuan cuaca hasil uji phisis secara terinci dapat dilihat pada lampiran 1 dan 2 , apabila dari data tersebut diadakan rata-rata maka rekapitulasinya terdapat pada lampiran 3 dan 4

Berdasarkan data uji sifat phisis dapat diketahui bahwa kulit jadi yan berasal dari berbagai jenis setelah mendapatkan perlakuan cuaca ternyata me ngalami perubahan sifat baik tegangan putus maupun perpanjangan putusnya adapun perubahan yang terjadi pada sifat tegangan putus cenderung menurun bila dibandingkan dengan cuplikan yang berasal dari blanko, sedangkan sifa perpanjangan putusnya perubahan yang terjadi sebaliknya yaitu semakin bertambah besar bila dibandingkan dengan cuplikan yang tidak mendapatkan perlakuan cuaca.

Adanya suatu kenaikkan ataupun penurunan sifat dari berbagai jenis kulit yang memperoleh perlakuan cuaca, akan tampak lebih jelas bila disajikan da lam bentuk prosentase perubahan seperti yang tampak pada tabel berikut :

Tabel 1 : Prosentase perubahan tegangan putus berbagai jenis kulit.

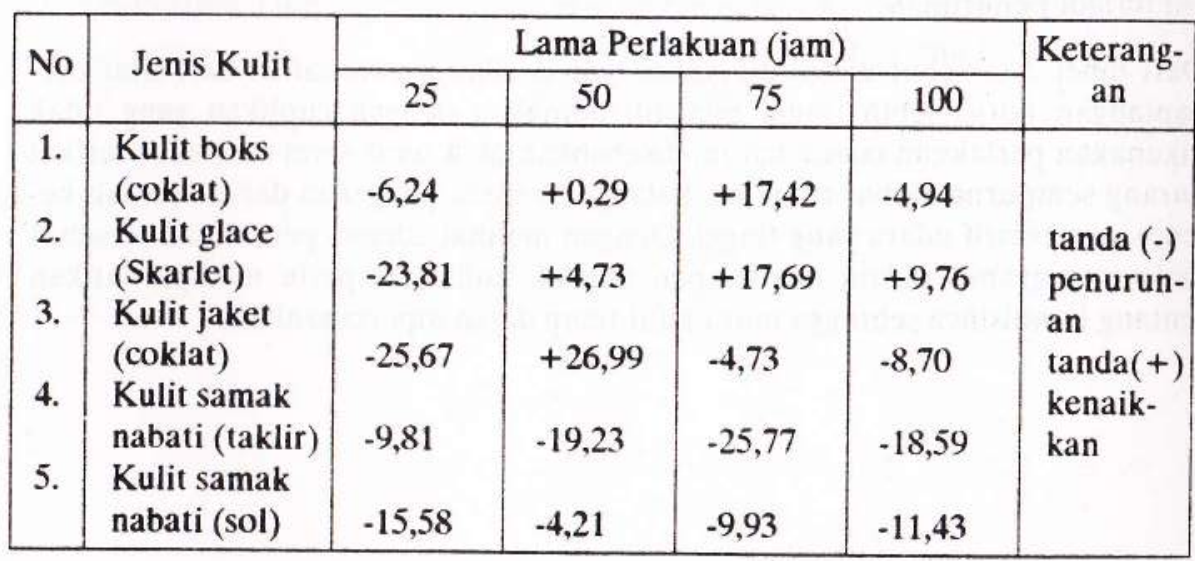

Perubahan yang terjadi pada sifat tegangan putus seperti pada tabel 1 diatas dimungkinkan karena kolagen yang mempunyai peran terhadap sifat phisis kulit mengalami kerusakan akibat dari kondisi yang lingkungan baik yang berupa panas maupun adanya kelembapan udara yang tinggi sehingga

Vol. IX No. 16 Tahun 1993/1994 
adorong terjadinya hidrolisa pada kolagen yang menyebabkan terjadinya petusan rantai polipeptida, sehingga dengan demikian terjadi penurunan sifat i berbagai jenis kulit yang diteliti termasuk diantaranya sifat perpanjangan us yang prosentase perubahannya seperti terdapat pada tabel 2 beriktu :

Tabel 2 : Prosentase perubahan perpanjangan putus berbagai kulit.

\begin{tabular}{|l|l|l|l|c|}
\hline \multirow{2}{*}{ Jenis kulit } & \multicolumn{4}{|c|}{ Lama perlakuan (jam) } \\
\cline { 2 - 5 } & \multicolumn{1}{|c|}{25} & 50 & 75 & 100 \\
\hline Kulit boks coklat & $+9,54$ & $+7,88$ & $+5,54$ & $+9,54$ \\
Kulit glace (skar- & $-21,24$ & $-6,72$ & $+1,55$ & $+9,84$ \\
let & & & & \\
Kulit jaket coklat & $+3,16$ & $+12,22$ & $+14,00$ & $+3,17$ \\
Kulit samak babati & $-8,77$ & $+5,26$ & $+26,32$ & $+22,87$ \\
(taklir) & & & & \\
Kulit samak nabati & $-12,12$ & $-15,15$ & $-9,09$ & $+9,09$ \\
(sol) & & & & \\
\hline
\end{tabular}

terjadi kenaikan

terjadi penurunan

i tabel 2 tersebut diatas diketahui bahwa adanya perubahan dari sifat perjangan putus lebih tinggi bila dibandingkan dengan cuplikan yang tidak nakan perlakuan cuaca, hal ini disebabkan oleh serat-serat dari kulit terikat ang sempurna akibat rusaknya kolangen karena pengaruh dari suhu dan kebapan relatif udara yang tinggi. Dengan melihat adanya perubahan tersebut a seyogyanya dalam menyimpan produk kulit jadi perlu memperhatikan ang kondisinya sehingga mutu kulit tetap dapat dipertahankan.

\section{Kesimpulan.}

Dari berbagai jenis produk kulit jadi yang dikenakan perlakuan cuaca dengan menggunakan alat Weather - Ometer ternyata mengalami perubahan sebagai berikut :

1. Sifat phisis tegangan putus mengalami perubahan menjadi lebih rendah bila dibandingkan dengan cuplikan yang tidak mendapat perlakuan cuaca.

2. Sifat phisis perpanjangan putus mengalami perubahan menjadi lebih besar dari pada yang tidak mendapatkan perlakuan cuaca.

\section{Daftar Pustaka.}

1. RYSZTOF BIENKIEWICZ

2. V. Sri Pertiwi. Dkk
"Physical Chemistry of Leather Making" Robert E. Krieger Publishing Company Malabar, Florida 1983.

"Hubungan antara kekuatan tarik dan kemuluran kulit untuk atasan sepatu," BBKKP 1988. 


\section{LAMPIRAN - LAMPIRAN}

Tabel 3 : HASIL UJI KUAT TARIK DENGAN DAN TANPA PERLAKUAN WOM BERBAGAI JENIS KULIT

\begin{tabular}{|c|c|c|c|c|c|c|c|c|c|}
\hline \multirow[b]{2}{*}{ No } & \multirow[b]{2}{*}{ Jenis Kulit } & \multicolumn{4}{|c|}{ Tanpa Perlakuan wom } & \multicolumn{4}{|c|}{ Perlakuan wom } \\
\hline & & $25 \mathrm{jam}$ & 50 jam & 75 jam & $\begin{array}{l}100 \\
\text { jam }\end{array}$ & 25 jam & 50 jam & 75 jam & $\begin{array}{l}100 \\
\text { jam }\end{array}$ \\
\hline \multirow[t]{3}{*}{1.} & $\begin{array}{l}\text { Kulit boks } \\
\text { (coklat) }\end{array}$ & & & & & & & & \\
\hline & Ulangan I & 386,90 & 457,22 & 395,45 & 394,94 & 383,99 & 321,08 & 530,30 & 401,23 \\
\hline & Ulangan II & 399,59 & 402,27 & 367,77 & 403,16 & 366,44 & 483,09 & 411,26 & 368,97 \\
\hline \multirow[t]{3}{*}{2.} & $\begin{array}{l}\text { Kulit Glace } \\
\text { (Skarlet) }\end{array}$ & & & & & & & & \\
\hline & Ulangan I & 255,00 & 355,26 & 284,09 & 244,32 & 225,52 & 318,75 & 325,00 & 350,00 \\
\hline & Ulangan II & 269,36 & 315,48 & 278,07 & 250,00 & 203,37 & 272,73 & 337,50 & 267,86 \\
\hline \multirow[t]{3}{*}{3.} & $\begin{array}{l}\text { Kulit jaket } \\
\text { (coklat) }\end{array}$ & & & & & & & & \\
\hline & Ulangan I & 92,86 & 133,33 & 206,61 & 145,45 & 95,24 & 118,18 & 101,45 & 95,24 \\
\hline & Ulangan II & 75,00 & 100,00 & 106,06 & 114,29 & 85,67 & 190,91 & 130,43 & 126,98 \\
\hline 4. & $\begin{array}{l}\text { Kulit samak } \\
\text { Nabati } \\
\text { (teklir) }\end{array}$ & & & & & & & & \\
\hline & Ulangan I & 295,61 & 311,50 & 278,07 & 338,89 & 253,62 & 275,74 & 272,73 & 283,75 \\
\hline 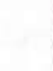 & Ulangan II & 338,62 & 312,50 & 288,77 & 307,49 & 304,53 & 224,09 & 186,67 & 220,09 \\
\hline \multirow[t]{3}{*}{5.} & $\begin{array}{l}\text { Kulit samak } \\
\text { Nabati (sol) }\end{array}$ & & & & & & & & \\
\hline & Ulangan I & 206,61 & 240,06 & 285,00 & 259,36 & 198,76 & 257,89 & 217,17 & 195,95 \\
\hline & Ulangan II. & 211,42 & 269,29 & 253,44 & 244,04 & $+251,62$ & 209,89 & 222,67 & 236,56 \\
\hline
\end{tabular}

Tabel 4 : HASIL UJI KEMULURAN BERBAGAI JENIS KULIT DENGAN DAN TANPA PERLAKUAN WOM.

\begin{tabular}{|c|c|c|c|c|c|c|c|c|c|}
\hline \multirow[b]{2}{*}{ No. } & \multirow[b]{2}{*}{ Jenis Kulit } & \multicolumn{4}{|c|}{ Tanpa Perlakuan wom } & \multicolumn{4}{|c|}{ Perlakuan wom } \\
\hline & & $25 \mathrm{jam}$ & 50 jam & 75 jam & $\begin{array}{l}100 \\
\text { jam }\end{array}$ & 25 jam & 50 jam & 75 jam & $\begin{array}{l}100 \\
\text { jam }\end{array}$ \\
\hline 1. & $\begin{array}{l}\text { Kulit boks } \\
\text { (coklat) }\end{array}$ & & & & & & & & \\
\hline & Ulangan I & 62 & 52 & 62 & 58 & 68 & 66 & 60 & 70 \\
\hline & Ulangan II & 62 & 60 & 66 & 60 & 64 & 64 & 72 & 62 \\
\hline 2. & $\begin{array}{l}\text { Kulit Glace } \\
\text { (Skarlet) }\end{array}$ & & & & & & & & \\
\hline & Ulangan I & 40 & 48 & 50 & 44 & 36 & 46 & 52 & 64 \\
\hline & Ulangan II & 42 & 48 & 58 & 56 & 40 & 44 & 46 & 42 \\
\hline 3. & $\begin{array}{l}\text { Kulit jaket } \\
\text { (coklat) }\end{array}$ & & & & & & & & \\
\hline & Ulangan I & 52 & 56 & 56 & 44 & 56 & 60 & 68 & 56 \\
\hline & Ulangan II & 56 & 56 & 58 & 62 & 58 & 64 & 58 & 58 \\
\hline 4. & $\begin{array}{l}\text { Kulit samak } \\
\text { Nabati } \\
\text { (teklir) }\end{array}$ & & & & & & & & \\
\hline & Ulangan I & 32 & 26 & 24 & 36 & 28 & 28 & 36 & 40 \\
\hline & Ulangan II & 26 & 24 & 28 & 34 & 24 & 32 & 36 & 30 \\
\hline 5. & $\begin{array}{l}\text { Kulit } \\
\text { Samak } \\
\text { Nabati (sol) }\end{array}$ & & & & & & & & \\
\hline & Ulangan I & 36 & 30 & 34 & 38 & 26 & 30 & 34 & 36 \\
\hline & Ulangan II & 26 & 34 & 32 & 34 & 32 & 26 & 26 & 36 \\
\hline
\end{tabular}


Tabel 5 : HASIL UJI RATA-RATA TEGANGAN PUTUS BERBAGAI JENIS KULIT

\begin{tabular}{|c|c|c|c|c|c|c|c|c|}
\hline \multirow[b]{2}{*}{ Jenis Kulit } & \multicolumn{4}{|c|}{ Tanpa Perlakuan wom } & \multicolumn{4}{|c|}{ Perlakuan wom } \\
\hline & 25 jam & $50 \mathrm{jam}$ & 75 jam & $\begin{array}{l}100 \\
\text { jam }\end{array}$ & 25 jam & 50 jam & 75 jam & $\begin{array}{l}100 \\
\text { jam }\end{array}$ \\
\hline $\begin{array}{l}\text { Kulit boks } \\
\text { (coklat) }\end{array}$ & 393,25 & 429,75 & 381,61 & 399,05 & 375,22 & 402,09 & 470,78 & 381,10 \\
\hline $\begin{array}{l}\text { Kulit Glace } \\
\text { (Skarlet) }\end{array}$ & 262,18 & 335,37 & 281,08 & 247,16 & 214,45 & 294,75 & 331,25 & 308,93 \\
\hline $\begin{array}{l}\text { Kulit jaket } \\
\text { (coklat) }\end{array}$ & 83,93 & 116,67 & 156,34 & 129,87 & 90,46 & 154,55 & 115,94 & 111,11 \\
\hline $\begin{array}{l}\text { Kulit samak } \\
\text { Nabati } \\
\text { (teklir) }\end{array}$ & 317,12 & 312,00 & 284,42 & 323,69 & 279,08 & 249,92 & 229,70 & 251,92 \\
\hline $\begin{array}{l}\text { Kulit } \\
\text { Samak } \\
\text { Nabati (sol) }\end{array}$ & 209,02 & 246,72 & 269,22 & 251,70 & 206,19 & 233,89 & 219,92 & 216,26 \\
\hline
\end{tabular}

Tabel 6: HASIL UJI RATA-RATA PERPANJANGAN PUTUS BERBAGAI JENIS KULIT

\begin{tabular}{|c|c|c|c|c|c|c|c|c|c|}
\hline \multirow[b]{2}{*}{ No. } & \multirow[b]{2}{*}{ Jenis Kulit } & \multicolumn{4}{|c|}{ Tanpa Perlakuan wom } & \multicolumn{4}{|c|}{ Perlakuan wom } \\
\hline & & 25 jam & 50 jam & 75 jam & $\begin{array}{l}100 \\
\text { jam }\end{array}$ & 25 jam & $50 \mathrm{jam}$ & 75 jam & $\begin{array}{l}100 \\
\text { jam }\end{array}$ \\
\hline 1. & $\begin{array}{l}\text { Kulit boks } \\
\text { (coklat) }\end{array}$ & 62 & 56 & 64 & 59 & 66 & 65 & 66 & 66 \\
\hline 2. & $\begin{array}{l}\text { Kulit Glace } \\
\text { (Skarlet) }\end{array}$ & 41 & 48 & 54 & 50 & 38 & 45 & 49 & 53 \\
\hline 3. & $\begin{array}{l}\text { Kulit jaket } \\
\text { (coklat) }\end{array}$ & 54 & 56 & 57 & 54 & 57 & 62 & 63 & 57 \\
\hline 4. & $\begin{array}{l}\text { Kulit samak } \\
\text { Nabati } \\
\text { (teklir) }\end{array}$ & 29 & 24 & 26 & 35 & 26 & 30 & 36 & 35 \\
\hline 5. & $\begin{array}{l}\text { Kulit } \\
\text { Samak } \\
\text { Nabati (Sol) }\end{array}$ & 31 & 32 & 33 & 36 & 29 & 28 & 30 & 36 \\
\hline
\end{tabular}




\section{RALAT}

MAJALAH BARANG KULIT, KARET DAN PLASTIK VOL. VIII NO. 15 TAHUN 1992 / 1993

\begin{tabular}{c|l|l}
\hline No. & \multicolumn{1}{|c|}{ Tertulis } & \multicolumn{1}{c}{ Seharusnya } \\
\hline 1. & $\begin{array}{l}\text { Hal. 40 } \\
\text { Baris terakhir ditulis bibit } \\
\text { unggul serta ... }\end{array}$ & $\begin{array}{l}\text { bibit unggul serta pelaksanaan } \\
\text { pembibitan tanaman skala } \\
\text { besar. }\end{array}$ \\
\hline 2. & $\begin{array}{l}\text { Hal. 41 } \\
\text { Baris keenam dari atas Kantong } \\
\text { Plastik banayk digunakan kan- } \\
\text { tong plastik yang mempunyai }\end{array}$ & $\begin{array}{l}\text { Kantong plastik banyak diguna- } \\
\text { kan dalam pembibitan tanaman } \\
\text { industri. Mengingat bahwa } \\
\text { penggunaan kantong plastik da- } \\
\text { lam bidang pertanian berada } \\
\text { pada tempat terbuka dan kon- } \\
\text { tak langsung dengan sinar ma- } \\
\text { tahari, air, hujan dan debu, } \\
\text { maka diperlukan kantong plas- } \\
\text { tik yang dst ....... }\end{array}$ \\
\hline
\end{tabular}

